\title{
BMJ Global Health Primary prevention of cardiovascular disease through population-wide motivational strategies: insights from using smartphones in stroke prevention
}

\author{
Valery L Feigin, ${ }^{1}$ Bo Norrving, ${ }^{2}$ George A Mensah ${ }^{3}$
}

To cite: Feigin VL, Norrving B, Mensah GA. Primary prevention of cardiovascular disease through population-wide motivational strategies: insights from using smartphones in stroke prevention. BMJ Global Health 2017;2:e000306. doi:10.1136/bmjgh-2017000306

Received 30 January 2017 Accepted 27 February 2017

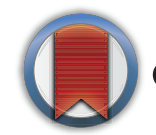

CrossMark

\footnotetext{
${ }^{1}$ Faculty of Health and Environmental Sciences, National Institute for Stroke and Applied Neurosciences, School of Public Health and Psychosocial Studies, Auckland University of Technology, Auckland, New Zealand

${ }^{2}$ Department of Clinical Sciences, Neurology, Skane University Hospital, Lund University, Lund, Sweden ${ }^{3}$ Center for Translation Research and Implementation Science (CTRIS), National Heart, Lung, and Blood Institute, National Institutes of Health, Bethesda, Maryland, USA
}

Correspondence to Professor Valery L Feigin; valery.feigin@aut.ac.nz

\section{ABSTRACT \\ The fast increasing stroke burden across all countries of the world suggests that currently used primary stroke and cardiovascular disease (CVD) prevention strategies are not sufficiently effective. In this article, we overview the gaps in, and pros and cons of, population-wide and high-risk prevention strategies. We suggest that motivating and empowering people to reduce their risk of having a stroke/CVD by using increasingly used smartphone technologies would bridge the gap in the population-wide and high-risk prevention strategies and reduce stroke/CVD burden worldwide. We emphasise that for primary stroke prevention to be effective, the focus should be shifted from high-risk prevention to prevention at any level of CVD risk, with the focus on behavioural risk factors. Such a motivational population-wide strategy could open a new page in primary prevention of not only stroke/CVD but also other non-communicable disorders worldwide.}

\section{INCREASING BURDEN OF STROKE}

Although the incidence and mortality rates of stroke and other cardiovascular diseases (CVDs) are declining, ${ }^{1}$ the absolute number of people affected by and remaining disabled from stroke has increased significantly at the global, regional and country-specific levels. Globally, the number of deaths from stroke has increased by $41 \%$, incident strokes by $66 \%$ and prevalent strokes by $84 \% .^{2-4}$ There is virtually no country in the world where the absolute number of incident, fatal or prevalent strokes or disability-adjusted life years (DALYs) lost associated with stroke has decreased over that period of time. ${ }^{25}$

Although ageing and population growth were shown to be the main drivers of the increased CVD (including stroke) mortality in the world, ${ }^{6}$ not all of the increased stroke burden can be accounted for by these demographic changes. For example, the proportional contribution of DALYs and deaths due

\section{Key questions}

What is already known about this topic?

- Stroke and cardiovascular disease (CVD) burden is increasing across the globe.

- There are two primary prevention strategies for stroke and CVD: mass or population-wide prevention and high-risk prevention.

What are the new findings?

- Currently used primary stroke/cardiovascular disease (CVD) prevention strategies are not effective enough and there are major gaps in primary stroke prevention strategies.

- Mobile technologies offer new promising ways of bridging the gap between population-wide and high-risk prevention strategies and enhancing primary stroke/CVD prevention.

\section{Recommendations for policy}

- The emphasis in primary stroke/cardiovascular disease (CVD) prevention should be shifted from high-risk prevention to prevention at any level of CVD risk, with the focus on behavioural risk factors.

- The proposed features of mobile technology to motivate and empower people to reduce their risk of stroke/CVD can help to reduce stroke/ CVD burden across the globe and open up a new, 'motivational population-wide', universally accessible and effective strategy for primary prevention of other major non-communicable disorders.

to stroke globally compared with all diseases from 1990 to 2013 increased by $31 \%$ and $22 \%$, respectively. Stroke is now no longer a disease of the elderly, with more than $60 \%$ of all strokes occurring in people aged $<65$ years. $^{7} 8$ Furthermore, in 2015, stroke moved for the first time from the third to the second largest cause of DALYs in the world. ${ }^{1}$ These changes in the proportional contribution of stroke burden to the overall burden from all other diseases and the trend 
towards affecting younger populations cannot be explained by these demographic changes alone.

Similar global negative trends were also observed for CVD and other non-communicable disorders (NCDs) and risk factors, especially for behavioural risk factors, overweight and diabetes mellitus, ${ }^{9}{ }^{10}$ prompting the United Nations (UN) to develop a special NCDs Declaration, ${ }^{11}$ followed by the WHO Global Action $\operatorname{Plan}^{12}$ on NCDs to attain a global target of a $25 \%$ reduction in premature deaths from NCDs. ${ }^{13}$ If the current trend in stroke burden continues, stroke will likely become the major cause of death and disability worldwide. Moreover, recent GBD 2015 Study estimates demonstrated that none of the 188 participating countries currently meets all of the UN's health-related sustainable development goals $(\mathrm{SDGs})^{14}$ and that the median health-related SDG index in 2015 was only 56.2 (out of 100 maximum possible).

This then raises questions on the achievability of the WHO NCDs Global Action Plan and health-related SDGs by 2025. For example, in a recent editorial of The Lancet, it was stated that without a rapid increase in action, the WHO target of a $10 \%$ reduction in physical inactivity by 2025 will not be reached. ${ }^{15}$ These large increases in stroke/CVD burden and risk factors strongly suggest that currently used primary stroke/CVD prevention strategies are not sufficiently effective. ${ }^{5}$ Given the highly preventable nature $(>90 \%)$ of stroke and CVD, ${ }^{9} 1617$ the question is why currently used stroke/ CVD primary prevention strategies are not sufficiently effective and what can be performed to improve primary stroke/CVD prevention on individual and population levels. Let us first consider what primary stroke/CVD prevention strategies are currently available, what gaps and challenges exist with their use and what can be performed to improve primary prevention.

\section{MASS STRATEGY AND HIGH-RISK STRATEGY: PROS AND CONS}

In 1981, Geoffrey Rose laid a foundation for a mass (population-wide) strategy ${ }^{18}$ as the most effective strategy for primary stroke/CVD prevention. Apart from the large population-wide effect of even a minor shift in the distribution of risk factors in the population, the huge advantage of the primary population-wide strategy is that it allows prevention of not only stroke/CVD but a wide range of other non-communicable diseases (NCDs) that share common risk factors, including cancer and diabetes.

However, population-wide strategy requires policy and legislative changes that are often not supported by major industries (eg, salt reduction in processed food, reduction in exposure to smoking, alcohol, fast food) and, therefore, is very difficult to implement. For example, although cigarettes were recognised as the cause of the lung cancer epidemic in 1950 and the first Public Health Cigarette Smoking Act was introduced in the USA in 1969, it took several decades before various policies towards smoking reduction on an international level started being implemented worldwide, and even now smoking remains one of the largest contributors to the burden of stroke/CVD ${ }^{91617}$ and other major NCDs in the world. ${ }^{10}$ In addition, population-wide primary prevention often requires substantial investments (eg, setting up affordable and widely accessible health outlets, affordable healthy foods and facilities for adequate physical activities to integrate physical activity into our daily lives ${ }^{15}$ ).

Governmental actions are political decisions that often meet resistance from the population/voters or from non-state actors, such as industry. As acknowledged by the UN General Assembly in 2014, there has been very slow, insufficient and uneven progress in the governmental mass strategy prevention programmes. ${ }^{13}$ All these challenges make the population-wide primary stroke/ CVD prevention strategy very difficult to implement on a national level and, although the mass strategy was suggested by Rose 35 years ago, there is still no country in the world where this strategy is fully implemented. Despite a special 2011 NCDs UN Declaration to have a NCDs prevention plan in every country in $2016,{ }^{11}$ most countries still do not have such plan.

Since the publication of Rose's 1981 paper and his subsequent research on high-risk and population-wide prevention strategies, there have been significant improvements in the accuracy of identification of high stroke/CVD risk individuals, which, as noted by McLaren $e a^{19}$ in 2009, led some to believe it was necessary 'to reduce or obviate the need for population prevention strategies in favour of high-risk strategies'. Unlike mass or population-wide primary prevention strategy when preventive interventions (reduction in exposure to risk factors and increase in exposure to potentially healthy, protective factors) are introduced to the whole population regardless of their baseline level of risk for stroke/CVD, the high-risk prevention strategy implies screening of the population to identify people with increased absolute risk of stroke/CVD. ${ }^{2021}$

In 2007, there was a 'Head to Head' debate in the British Medical Journal between Jackson et $a l^{22}$ who argued that screening individuals at high risk of CVD would be effective as well as cost-effective and Capewell $^{23}$ who argued that whole population approaches would be more cost-effective. In our opinion, although high-risk strategy is good at taking an integrative approach for primary stroke/CVD prevention and can be used as a guide for making clinical decisions on the intensity and effectiveness of preventive interventions, ${ }^{19}{ }^{24}$ it has a number of significant limitations. ${ }^{5}$ Moreover, the most recent evidence has proven that opponents of the high-risk strategies were correct. It has recently been estimated that high-risk strategy theoretically could, at best, reduce CVD incidence by $11 \%,{ }^{25}$ but evidence from the most recent 15 randomised controlled trials (over 240000 patients, including Cochrane Systematic Review) ${ }^{26} 27$ convincingly showed that just 
screening of the population for CVD risk, even when combined with some counselling, is not effective at all (compared with the current preventive strategies) for reducing stroke/CVD incidence and mortality on a population level.

This situation with the high-risk strategy may be described as Rose's 'prevention paradox', just the other way around-'a measure that brings benefits to high-risk individuals offers little to the community'. On the other hand, evidence from the North Karelia Project and two other subnational studies have confirmed the effectiveness of the population-wide strategy for stroke/CVD prevention. ${ }^{28-30}$ However, despite this compelling body of evidence, the high-risk approach is still being used in preference over the population-wide approach. ${ }^{25}$

\section{MAJOR GAPS IN PRIMARY STROKE/CVD PREVENTION}

Current primary stroke prevention strategies are not sufficiently effective, ${ }^{31}$ as there are several gaps in prevention.

1. Lack of awareness: Despite the evidence for modifying health behaviour, ${ }^{32}$ the level of public awareness of stroke, its risk factors and management is low. ${ }^{33}$ This means that behaviour modification is suboptimal and can (and should) be greatly enhanced;

2. Underusage of population-wide strategies: In 2008, Capewell $^{23}$ argued that the greatest danger arising from the high-risk approach is that it is "misleading professionals, planners and politicians into thinking they can tick the mission accomplished box for preventing cardiovascular disease'. The lack of use of the population-wide prevention strategy and unreasonably excessive focus on high-risk prevention strategies have been suggested as the main reasons for the lack of efficiency of the currently used primary stroke/ CVD prevention; ${ }^{5}$

3. False reassurance of low risk: Current primary prevention strategies recommendations primarily target people with moderate to high absolute CVD risk. ${ }^{34}$ Individuals labelled as 'low risk' are falsely reassured and not motivated to reduce their risk, despite many having several modifiable risk factors. Indeed, $~ 80 \%$ of strokes occur in people categorised as having low absolute risk. ${ }^{35}$ In a recent Editorial in the International Journal of Epidemiology, ${ }^{36}$ Chiolero et al wrote that "a fundamental failure of high-risk prevention strategies is their inability to prevent disease in the large part of the population at a relatively small average risk and from which most cases of disease originate." Therefore, the majority of the population is effectively left out of preventive interventions. It was also suggested that in communicating absolute CVD risk, categorisation of people into low, moderate (mild) and high risk should be abandoned; ${ }^{5}$

4. Management of blood pressure: The current stroke/CVD absolute risk assessment guidelines ${ }^{20} 3437$ management approach is based on overall CVD risk. Thus, individuals with blood pressures (BP) higher than 140/90 mm Hg, which conventionally defines hypertension, ${ }^{38}$ may not be treated with antihypertensive medication because of a 5 -year absolute CVD risk below $15 \% .^{39}$ However, elevated BP is an important modifiable risk factor and has been identified as a leading cause of stroke/CVD burden worldwide, ${ }^{9} 1617$ and therefore should be controlled appropriately; ${ }^{9}$

5. Important stroke risk factors missed from screening: With the exception of smoking, behavioural risk factors such as poor diet, sedentary lifestyle, chronic stress, overweight and excessive alcohol intake are not usually included in the stroke/CVD risk algorithms that are currently used. This is despite the fact that nearly three-quarters of the global burden of stroke is linked to lifestyle choices. ${ }^{9}$

6. Low specificity of the CVD prediction algorithms: Most of the currently used CVD/stroke prediction algorithms are based on the Framingham study of a primarily white population of North America, which may not be accurate enough for other racial/ethnic groups. ${ }^{37}$

7. Cost barrier. Seeing a physician for a CVD risk assessment is a cost barrier for some, especially for people in low to medium-income countries, hence a low-cost method of risk assessment is needed to address this issue. In addition, screening programmes for identifying high-risk individuals require considerable efforts and cost, therefore unlikely to be widely implemented in resource-poor countries and socially disadvantaged populations, even in high-income countries.

\section{BRIDGING THE GAP BETWEEN MASS AND HIGH-RISK STRATEGIES}

Recent advances in mobile (smartphone) technologies and their worldwide use (about 2 billion estimated users in 2015) ${ }^{40}$ offer unique opportunities to use these technologies for improving health and research capabilities. ${ }^{41}$ In a recent Scientific Statement of the American Heart Association (AHA) on consumer use of mobile health for CVD prevention, ${ }^{42}$ it was stated that mobile technologies have the potential to provide required information to counsel and motivate individuals to engage in behaviours to prevent CVD and 'to transform the delivery of health-related messages and on-going interventions targeting behaviour change'.

In recognition of the importance of e-research NCD initiatives, the UN Economic and Social Council, the International Telecommunication Union (ITU) and the WHO recently (June 2013) launched a new mHealth initiative for improving NCD prevention, treatment and policy enforcement. ${ }^{43}$ However, some health professionals raised concerns about the use of mobile technologies for primary prevention, such as likely low efficacy and sustainability of the prevention effect as well as the likely short usage of the app during the lifetime, distraction from more effective population-wide 
prevention strategies and widening inequalities between those who can afford smartphones and those who cannot.

Here, we would like to address these concerns, challenge Rose's 1981 statement ${ }^{18}$ that "we should not expect too much (in terms of prevention) from individual health education" and suggest a new, potentially highly effective population-wide app-based primary prevention strategy that can be used not only for stroke and CVD prevention but also for primary prevention of other NCDs.

\section{Low efficacy and sustainability of prevention effect}

There are a number of stroke/CVD and other NCD apps currently available in Apple Store and Google Play and there are several smartphone-based technologies and apps that were or are being used in clinical trials for managing particular medical conditions and risk factors (eg, CVD risk factor modification, healthy behavioural changes) ${ }^{44-52}$ with promising results. As stated by the AHA on the issue of mobile health for CVD prevention "the current absence of evidence should not be used as evidence of an absence of effectiveness. Instead we need to embrace the challenge of producing this needed evidence on how effective these new technologies are and how we can best adopt them in our practice to promote better patient care. ${ }^{42}$ A series of initiatives and grants to address gaps in digital health science are currently underway in the USA and many other countries. As to the educational component of the apps (eg, stroke warning signs, risk factors and how to control them based on the well-acknowledged international guidelines), this component of the apps needs no further evidence to be used as widely as possible.

\section{Short usage of the app during the lifetime}

This is probably the greatest challenge of the app development that needs to be addressed. To be used regularly for primary prevention, the app needs to be pro-actively requested by the user and meet several criteria, including to be easy-to-use, user-friendly, culturally appropriate, interactive and motivate the users to use it with the right periodicity as long as possible.

\section{Distraction from more effective population-wide prevention strategies}

We believe that mobile technologies for primary prevention should not be presented as alternatives for population-wide or even high-risk strategies but as an add-on tool to enhance primary prevention. Focusing on healthy behavioural modification, appropriate mobile technologies do not have an issue of medicalisation associated with high-risk approach.

\section{Widening inequalities between those who can afford smartphones and those who cannot}

This concern was correct when smartphones had only just entered the market and were not affordable for the majority of the population. Even in emerging and developing nations, smartphone ownership rates are rising at an extraordinary rate, climbing from a median of $21 \%$ in 2013 to $37 \%$ in $2015 .^{40}$ The number of smartphone users in the world is projected to reach 6.1 billion by $2020 .^{53}$ Thus, delivering primary prevention information via affordable (ideally free to download) mobile platforms, especially culturally appropriate and translated into the world's most spoken languages, may be the most efficient strategy to reduce inequalities in health education and primary prevention.

\section{Low efficacy of 'individual health education'}

In his 1981 paper, Geoffrey Rose emphasised the importance of motivation in achieving and sustaining healthy behaviour, but he looked at the issue from societal perspective. He stated: "to influence mass behaviour we must look to its mass determinants, which are largely economic and social." While the economic motivation (eg, taxation on cigarettes, salt, sugar, alcohol, saturated fat) and social motivation (eg, public unacceptability of smoking and other unhealthy health behaviours and social encouragement of healthy lifestyle/behaviour) are very important for effective primary population-wide prevention strategies, the already high and increasing usage of smartphones throughout the world offers an additional, not only motivational, but also health educational tool to enhance primary prevention on the personal level.

In the area of stroke and CVD, one promising way of motivating individuals to look after their health could be by showing them their relative risk or lifetime risk ${ }^{37} 54-56$ of having a disease, which is also far easier to understand by lay people than absolute risk. For example, a White/Caucasian man aged 35 years who smokes and has a $\mathrm{BP}$ of $140 / 85 \mathrm{~mm} \mathrm{Hg}$ has 2.9\% 10-year absolute risk of CVD (myocardial infarction or stroke as determined by ASCVD Risk Evaluation ${ }^{37} 57$ or similar PREDICT $^{58}$ algorithm), which is conventionally regarded as mild/low risk. If this individual is told that his risk of having CVD is mild/low, he (most likely) would believe that he is safe from CVD and would not be motivated to reduce his risk, even though he has two very significant risk factors for CVD (hypertension and smoking) that warrant adequate preventative interventions.

The ASCVD Risk Evaluation shows that the same individual's 10-year risk with optimal risk factors equals to $0.6 \%$, meaning that the relative risk of having CVD is almost 5 . The lifetime risk of that individual is $50 \%$ and $5 \%$ with optimal risk factors, meaning that his lifetime relative risk is 10 . It would be logical to assume that if the same individual were told that his CVD risk is $5-10$ times greater than someone of his age, sex and race/ ethnicity, he would be interested to know why his risk is so high and what he could do to reduce it. For the purpose of motivation, it has also been recommended to use various risk visualisation techniques. 565960 


\section{WHERE TO FROM HERE?}

For primary stroke prevention to be effective, the emphasis should be shifted from high-risk prevention to prevention at any level of CVD risk, with the focus on behavioural risk factors. It was recently suggested that motivating and empowering people to reduce their risk of having a stroke/CVD using increasingly used smartphone technologies would bridge the gap in the population-wide and high-risk prevention strategies and reduce stroke/CVD burden worldwide, ${ }^{55}$ even in developing countries such as Africa and India, ${ }^{61}$ where ownership of smartphones is already high and increasing. Evidence of the efficacy of smartphone technologies for management and prevention of CVD and other NCDs and risk factors is accumulating with promising results. ${ }^{44-46}$ 62-64 Capitalising on the mobile information technology that motivates and empowers people throughout the world to reduce their risk of having a
stroke/CVD represents a new paradigm in mass primary prevention, ${ }^{65}$ which we suggest calling 'motivational population-wide strategy.'

An example of this strategy is the validated Stroke Riskometer app,$^{55}$ 66-68 endorsed not only by all major international organisations (World Stroke Organization, World Federation of Neurology, World Heart Federation and European Stroke Organisation) but also an increasing number of national stroke organisations, including China Stroke Association, Australian Stroke Foundation and the National Russian Organisation for the Fight Against Stroke. In 2014, the app was voted by senior American doctors as the number 1 app in Medical Conditions among $100000+$ health-related apps worldwide, ${ }^{69}$ and since then has been downloaded $>100000$ times from over 100 countries.

The app not only empowers people to know their absolute risk (as many other CVD apps do) ${ }^{57} 7^{70}$ but also
Figure 1 Comparison of conventional population-based, high-risk and motivational population-wide cardiovascular disease (CVD) prevention strategies. Modified from WHO 'Cardiovascular disease prevention and control. Translating evidence into action'. ${ }^{72}$ (A) Population-based prevention strategy aimed at shifting the distribution of risk factors and associated CVD risk in the whole population towards optimal distribution of CVD risk (shadowed in grey area shows a theoretically possible proportion of the population that could benefit from this strategy); (B) high-risk prevention strategy aimed at treating the individuals at high absolute risk of CVD (shadowed in grey area shows a theoretically possible proportion of the population that could benefit from this strategy; with the $20 \%$ cut-off for 10 -year high CVD risk, only about $13 \%$ of the population could benefit from this strategy) $;^{73}(\mathrm{C})$ motivational population-wide CVD prevention strategy aimed at managing CVD risk factors in the individuals at the high relative risk of CVD (shadowed in grey area shows a theoretically possible proportion of the population that could benefit from this strategy; with two CVD risk factors, almost $80 \%$ of the population could benefit from this strategy) ${ }^{71}$
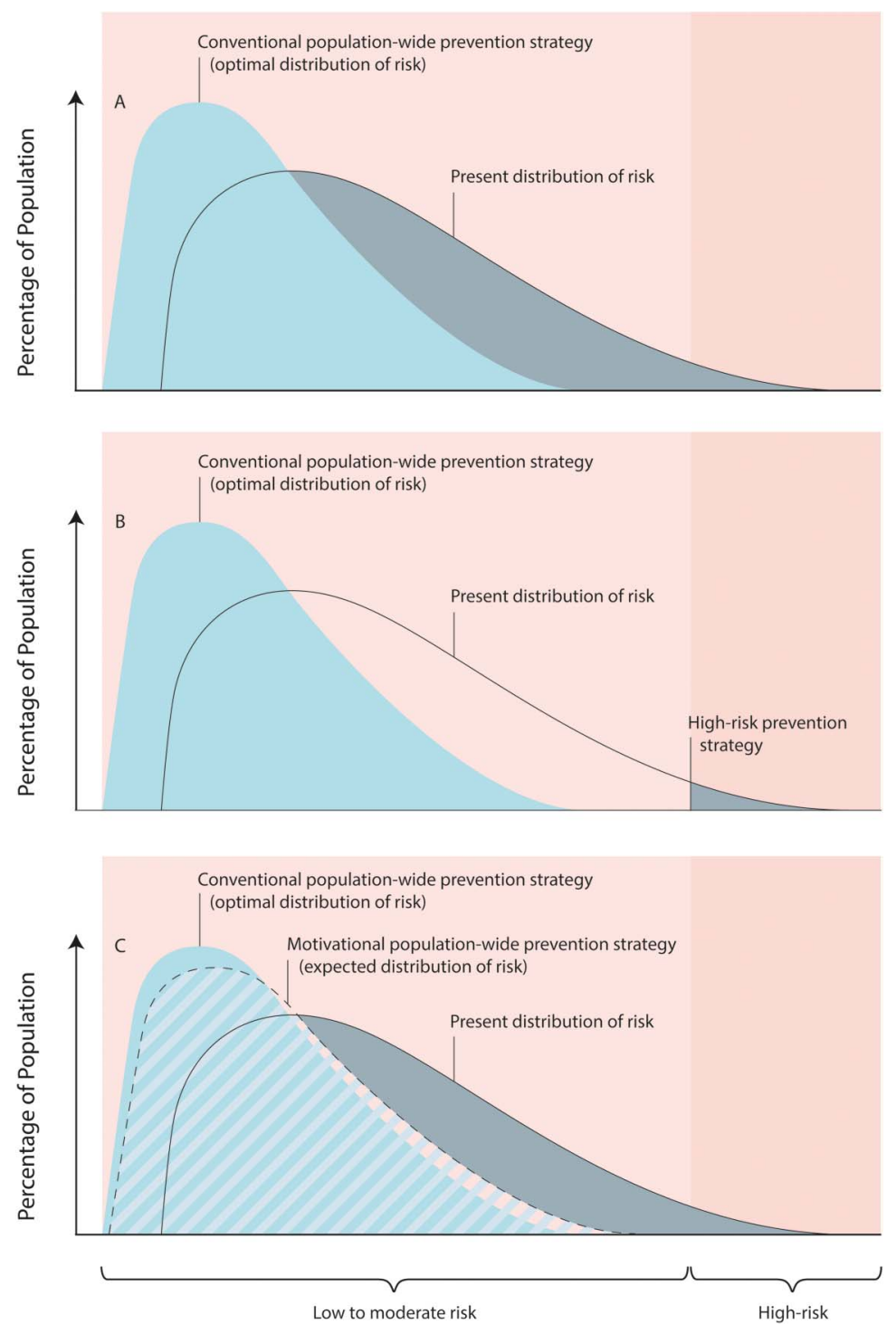
their relative risk of having a stroke within the next 510 years, thus motivating them to reduce their risk of stroke. For example, for an $82 \mathrm{~kg}, 170 \mathrm{~cm}$, man aged 25 years, with a poor diet $(<6$ servings of fruits/vegetables a day), not physically active enough and with systolic $\mathrm{BP}$ of $127 \mathrm{~mm} \mathrm{Hg}$, the 5-year absolute risk of having a stroke is only $0.65 \%$. However, this man's relative risk of having a stroke is 2.8 , and this, we believe, would motivate him to know why his risk is increased and what he can do to reduce it. As $78 \%$ of adults free of CVD have two or more modifiable CVD risk factors such as BP, cholesterol, glucose, body mass index, smoking, physical activity or diet, ${ }^{71}$ and therefore will have a noticeably increased relative risk of stroke shown in the app arguably sufficient to motivate them to reduce their risk, we believe that the effectiveness of the app in preventing stroke and other major NCDs that share common risk factors with stroke may be close to that of the mass strategy (figure 1). ${ }^{65}$

Apart from these risk factors, the app includes additional risk factors such as alcohol intake, stress, family history of CVD and diabetes; therefore, the proportion of adults free from CVD disease who have two or more CVD risk factors included in the app is likely to be noticeably $>78 \%$. The app also educates users about stroke warning signs (extended version of the Face-Arm-Speech-Time (F.A.S.T.)), their individual and overall risk factors and how to control them by using evidence-based and internationally recognised guidelines.

Unlike some costs associated with the implementation of population-wide primary prevention strategies and significant costs associated with screening of the population for implementation of high-risk prevention strategies, an app-based primary prevention strategy carries virtually no cost and there are no counterproductive stakeholders that may influence the individual's decision to reduce their risk of having a disease. It carries no risk of adverse events and is basically a 'nothing to lose' strategy.

There is evidence that a combination of populationwide and individual approach integrated into the primary care for CVD prevention is effective in reducing CVD mortality and also reduces socioeconomic inequalities in CVD mortality. ${ }^{74}$ By taking advantage of population-wide and high-risk prevention strategies and at the same time addressing their current limitations, these mobile technologies could be incorporated into the hospital and community patient management systems (figure 2), thus providing an important (currently missing) interface between patients and healthcare providers.

In addition, the app provides a unique research tool for collecting much needed epidemiological data on stroke and other major NCDs across the globe, and the international app-based epidemiological RIBURST study (Reducing the International Burden of Stroke Using Mobile Technology) ${ }^{55}$ is already underway. The Stroke Riskometer app is currently being piloted in New Zealand in a randomised controlled trial called MARS (Mobile Application to Reduce Risk of Stroke; ANZCTR Trial Registration Number ACTRN12616000376448p).

Preliminary results indicate the feasibility of recruitment and acceptability of the intervention by participants. Pilot findings showed that those randomised to the intervention group used the app at least one, but up to six, times in 3 months. The participants also provided positive feedback on the trial experience. For example; "That is awesome, to have an app do that. I am really
Figure 2 Integrating mobile technology with patient management systems.

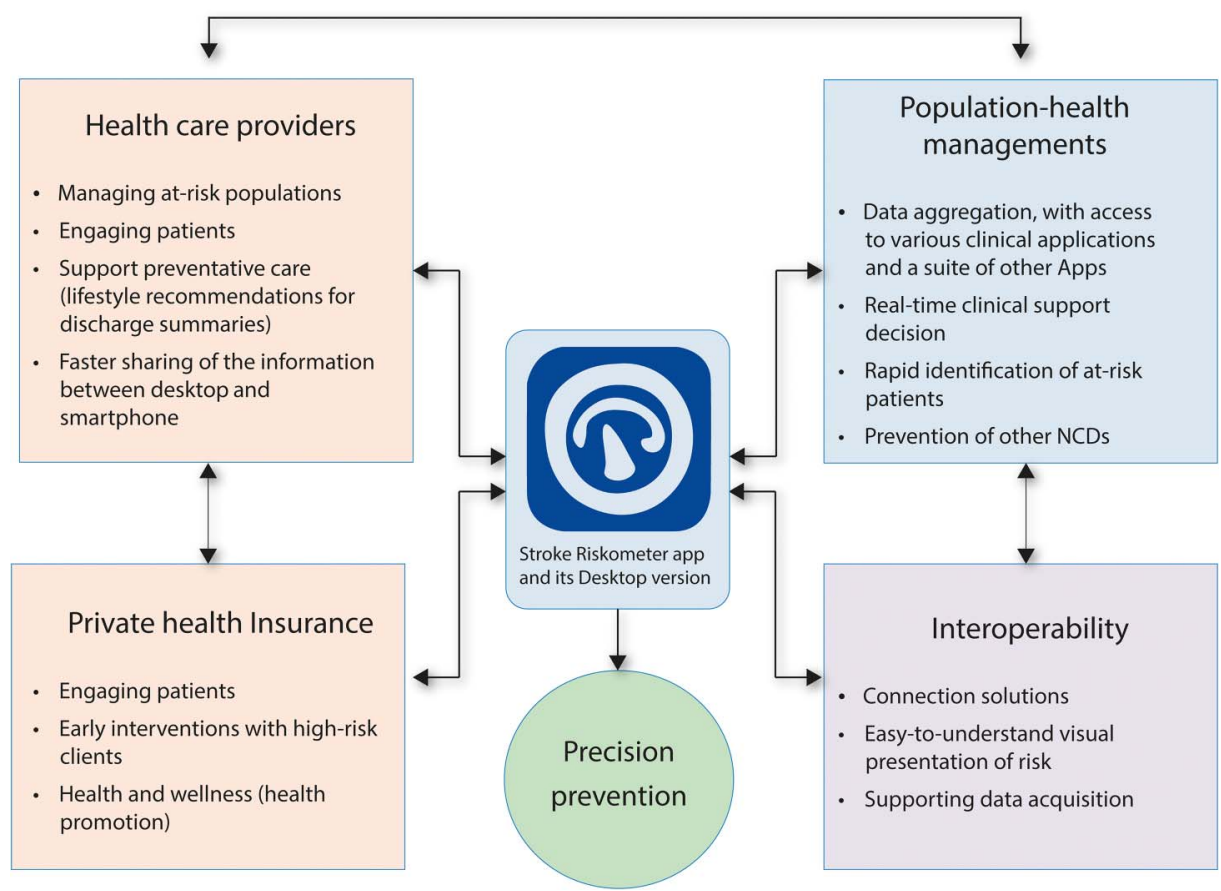


concerned about my health and want to do something about it, just need a motivation"; "My mum had a stroke. I know how it affects everyone. I want to live healthier for my family and my children"; "I have a partner who has had a stroke. I wasn't with him at the time but I want to understand it more and why it happens"; "I want to be a good role model for my kids. I want to show them how to live healthy and eat healthy." These quotes highlight the desire for people in the community to know more about stroke and take action for better health, and also the need for a tool that will allow them to do so, thus proving the motivational value of the app. The trial is expected to be completed by mid-2017.

With more than 300 collaborators in over 100 countries, the RIBURST study is one of the largest international epidemiological studies of stroke, myocardial infarction, dementia and type 2 diabetes mellitus in the world. The app has the potential to save millions of lives around the world, by being translated into the world's most spoken languages (covering over $90 \%$ of the world population), motivating and empowering people to reduce their risk of not only stroke but also other major NCDs that share common risk factors with stroke, such as ischaemic heart disease, dementia and diabetes mellitus. It was suggested that improving CVD health by improving control of CVD risk factors will also reduce the burden of cancer and other chronic disease. ${ }^{75}$ Such a motivational population-wide strategy could open a new page in primary prevention of not only stroke/CVD but also other NCDs worldwide.

In 2011, the WHO stated "The use of mobile and wireless technologies to support the achievement of health objectives (mHealth) has the potential to transform the face of health service delivery across the globe." ${ }^{.76}$ In the most recent paper on digital health for cardiovascular medicine published in JAMA Cardiology, ${ }^{77}$ Turakhia et al wrote: "Digital health is still in beta testing. However, its future is bright." We cannot agree more!

Contributors All authors researched data for the article, made substantial contributions to discussions of the content and reviewed and/or edited the manuscript before submission. VLF wrote the initial draft of the article.

Funding VLF was partly funded by the Health Research Council of New Zealand, the Brain Research New Zealand Centre of Research Excellence, the 'Ageing Well' Programme of the National Science Challenge and the Ministry of Business, Innovation and Employment of New Zealand. GAM has grant funding from the US National Institute on Ageing and Medtronic Philanthropy.

Disclaimer The views expressed in this article are those of the authors and do not necessarily represent the views of the Centers for Disease Control and Prevention; National Heart, Lung, and Blood Institute; National Institutes of Health; or the US Department of Health and Human Services.

Competing interests VLF is a principal investigator of the RIBURST study and a randomised controlled trial testing efficacy of Stroke Riskometer app for primary stroke prevention; he has served as a speaker for AstraZeneca and Bristol-Myers Squibb. VLF declares that the not-for-profit Stroke Riskometer app is copyrighted by the Auckland University of Technology (New Zealand), and any possible revenue from sales of Stroke Riskometer Pro version of the app will be used for research and educational purposes. The other authors declare no competing interests and have no conflicts to disclose.

Provenance and peer review Not commissioned; internally peer reviewed.
Data sharing statement No additional data are available.

Open Access This is an Open Access article distributed in accordance with the Creative Commons Attribution Non Commercial (CC BY-NC 4.0) license, which permits others to distribute, remix, adapt, build upon this work noncommercially, and license their derivative works on different terms, provided the original work is properly cited and the use is non-commercial. See: http:// creativecommons.org/licenses/by-nc/4.0/

\section{REFERENCES}

1. Vos T, Allen C, Arora M, et al. Global, regional, and national incidence, prevalence, and years lived with disability for 310 diseases and injuries, 1990-2015: a systematic analysis for the Global Burden of Disease Study 2015. Lancet 2016;388:1545-602.

2. Feigin VL, Krishnamurthi RV, Parmar $P$, et al. Update on the global burden of ischemic and hemorrhagic stroke in 1990-2013: the GBD 2013 study. Neuroepidemiology 2015;45:161-76.

3. Kassebaum NJ, Arora M, Barber RM, et al. Global, regional, and national disability-adjusted life-years (DALYs) for 315 diseases and injuries and healthy life expectancy (HALE), 1990-2015: a systematic analysis for the Global Burden of Disease Study 2015. Lancet 2016;388:1603-58.

4. Wang $\mathrm{H}$, Naghavi $\mathrm{M}$, Allen $\mathrm{C}$, et al. Global, regional, and national life expectancy, all-cause mortality, and cause-specific mortality for 249 causes of death, 1980-2015: a systematic analysis for the Global Burden of Disease Study 2015. Lancet 2016;388:1459-544.

5. Feigin VL, Norrving B, George MG, et al. Prevention of stroke: a strategic global imperative. Nat Rev Neurol 2016;12:501-12.

6. Roth GA, Forouzanfar MH, Moran AE, et al. Demographic and epidemiologic drivers of global cardiovascular mortality. $N$ Eng J Med 2015;372:1333-41.

7. Feigin VL, Forouzanfar MH, Krishnamurthi R, et al. Global and regional burden of stroke during 1990-2010: findings from the Global Burden of Disease Study 2010. Lancet 2014;383:245-55.

8. Krishnamurthi RV, Feigin VL, Forouzanfar MH, et al. Global and regional burden of first-ever ischaemic and haemorrhagic stroke during 1990-2010: findings from the Global Burden of Disease Study 2010. Lancet Glob Health 2013;1:e259-81.

9. Feigin VL, Roth GA, Naghavi M, et al. Global burden of stroke and risk factors in 188 countries, during 1990-2013: a systematic analysis for the Global Burden of Disease Study 2013. Lancet Neurol 2016;15:913-24.

10. Forouzanfar $\mathrm{MH}$, Alexander L, Anderson HR, et al. Global, regional, and national comparative risk assessment of 79 behavioural, environmental and occupational, and metabolic risks or clusters of risks in 188 countries, 1990-2013: a systematic analysis for the Global Burden of Disease Study 2013. Lancet 2015;386:2287-323.

11. United Nations General Assembly. Resolution adopted by the General Assembly: 66/2: Political Declaration of the High-level Meeting of the General Assembly on the Prevention and Control of Non-communicable Diseases. Adopted 19 September 2011. Published 24 January 2012. http://www.who.int/nmh/events/un_ncd_ summit2011/political_declaration_en.pdf

12. World Health Organization. Global action plan for the prevention and control of noncommunicable diseases 2013-2020. Geneva: WHO, 2013. http://wwwwhoint/nmh/events/ncd action_plan/en/ (4 Dec).

13. Chestnov O, Obermeyer W, St John J, et al. Towards the world we want. Bull World Health Organ 2014;92:623.

14. Lim SS, Allen K, Bhutta ZA, et al. Measuring the health-related Sustainable Development Goals in 188 countries: a baseline analysis from the Global Burden if Disease Study 2015. Lancet 2016;388:1813-50.

15. Das P, Horton R. Physical activity-time to take it seriously and regularly. Lancet 2016;388:1254-5.

16. Yusuf $S$, Hawken S, Ounpuu S, et al. Effect of potentially modifiable risk factors associated with myocardial infarction in 52 countries (the INTERHEART study): case-control study. Lancet 2004;364:937-52.

17. O'Donnell MJ, Chin SL, Rangarajan S, et al. Global and regional effect of potentially modifiable risk factors associated with acute stroke in 13,447 cases and 13,472 controls in 32 countries: INTERSTROKE case-control study. Lancet 2016;388:761-75.

18. Rose G. Strategy of prevention: lessons from cardiovascular disease. Br Med J (Clin Res Ed) 1981;282:1847-51.

19. McLaren L, Mclntyre L, Kirkpatrick S. Rose's population strategy of prevention need not increase social inequalities in health. Int J Epidemiol 2010;39:372-7.

20. Alliance NVDP. Guidelines for the management of absolute cardiovascular disease risk. Canberra: National Health and Medical Research Council of Australia, 2012. 
21. Heuschmann PU, Grieve AP, Toschke AM, et al. Ethnic group disparities in 10-year trends in stroke incidence and vascular risk factors: the South London Stroke Register (SLSR). Stroke 2008;39:2204-10.

22. Jackson $\mathrm{R}$, Wells $\mathrm{S}$, Rodgers $\mathrm{A}$. Will screening individuals at high risk of cardiovascular events deliver large benefits? Yes. BMJ 2008;337:a1371.

23. Capewell $\mathrm{S}$. Will screening individuals at high risk of cardiovascular events deliver large benefits? No. BMJ 2008;337:a1395.

24. World Health Organization. Prevention of cardiovascular disease: guidelines for assessment and management of cardiovascular risk. Geneva: WHO, 2007

25. Emberson J, Whincup P, Morris R, et al. Evaluating the impact of population and high-risk strategies for the primary prevention of cardiovascular disease. Eur Heart J 2004;25:484-91.

26. Krogsbøll LT, Jørgensen KJ, Grønhøj Larsen C, et al. General health checks in adults for reducing morbidity and mortality from disease: Cochrane systematic review and meta-analysis. BMJ 2012;345:e7191.

27. Jørgensen $\mathrm{T}$, Jacobsen RK, Toft $\mathrm{U}$, et al. Effect of screening and lifestyle counselling on incidence of ischaemic heart disease in general population: Inter99 randomised trial. BMJ 2014;348:g3617.

28. Puska P. Successful prevention of non-communicable diseases: 25 year experiences with North Karelia project in Finland. Public Health Med 2002;4:5-7.

29. Miura K. Epidemiology and prevention of hypertension in Japanese: how could Japan get longevity? EPMA J 2011;2:59-64.

30. Record NB, Onion DK, Prior RE, et al. Community-wide cardiovascular disease prevention programs and health outcomes in a rural county, 1970-2010. JAMA 2015;313:147-55.

31. Ebrahim S, Taylor F, Ward K, et al. Multiple risk factor interventions for primary prevention of coronary heart disease. Cochrane Database Syst Rev 2011;(1):CD001561.

32. Spring B, Ockene JK, Gidding SS, et al. Better population health through behavior change in adults: a call to action. Circulation 2013;128:2169-76.

33. Jones SP, Jenkinson AJ, Leathley MJ, et al. Stroke knowledge and awareness: an integrative review of the evidence. Age Ageing 2010;39:11-22.

34. Group NZG, editor. New Zealand primary care handbook. 3rd edn. Wellington: New Zealand Guidelines Group, 2012.

35. Dalton ARH, Soljak M, Samarasundera E, et al. Prevalence of cardiovascular disease risk amongst the population eligible for the NHS Health Check Programme. Eur J Prev Cardiol 2013;20:142-50.

36. Chiolero A, Paradis G, Paccaud F. The pseudo-high-risk prevention strategy. Int J Epidemiol 2015;44:1469-73.

37. Goff DCJr, Lloyd-Jones DM, Bennett G, et al. 2013 ACC/AHA guideline on the assessment of cardiovascular risk: a report of the American College of Cardiology/American Heart Association Task Force on Practice guidelines. J Am Coll Cardiol 2014;63(25 Part B):2935-59.

38. James PA, Oparil S, Carter BL, et al. 2014 Evidence-based guideline for the management of high blood pressure in adults: report from the panel members appointed to the Eighth Joint National Committee (JNC 8). JAMA 2014;311:507-20.

39. McLean RM, Williams S, Mann JI, et al. Blood pressure and hypertension in New Zealand: results from the 2008/09 Adult Nutrition Survey. N Z Med J 2013;126:66-79.

40. Pew Research Center. Global Attitudes \& Trends. Smartphone Ownership and Internet Usage Continues to Climb in Emerging Economies. 2016. http://www.pewglobal.org/2016/02/22/smartphoneownership-and-internet-usage-continues-to-climb-in-emergingeconomies/

41. Nasser FB, Trevena L. There's an app for that: a guide for healthcare practitioners and researchers on smartphone technology. Online J Public Health Inform 2015;7:e218.

42. Burke LE, Ma J, Azar KMJ, et al. Current science on consumer use of mobile health for cardiovascular disease prevention: a scientific statement from the American Heart Association. Circulation 2015;132:1157-213.

43. BE HE@LTHY, BE MOBILE 2014. http://www.itu.int/en/ITU-D/ICTApplications/eHEALTH/Pages/Be Healthy.aspx

44. Buller DB, Borland R, Bettinghaus EP, et al. Randomized trial of a smartphone mobile application compared to text messaging to support smoking cessation. Telemed J E Health 2013;20:206-14.

45. Carter MC, Burley VJ, Nykjaer C, et al. Adherence to a smartphone application for weight loss compared to website and paper diary: pilot randomized controlled trial. J Med Internet Res 2013;15:e32.

46. Chow CK, Redfern J, Hillis GS, et al. Effect of lifestyle-focused text messaging on risk factor modification in patients with coronary heart disease: a randomized clinical trial. JAMA 2015;314:1255-63.
47. Ganesan AN, Louise J, Horsfall M, et al. International mobile-health intervention on physical activity, sitting, and weight: the Stepathlon Cardiovascular Health Study. J Am Coll Cardiol 2016;67:2453-63.

48. Urrea B, Misra S, Plante TB, et al. Mobile health initiatives to improve outcomes in primary prevention of cardiovascular disease. Curr Treat Options Cardiovasc Med 2015;17

49. Piette JD, List J, Rana GK, et al. Mobile health devices as tools for worldwide cardiovascular risk reduction and disease management. Circulation 2015;132:2012-27.

50. Pfaeffli Dale L, Dobson R, Whittaker R, et al. The effectiveness of mobile-health behaviour change interventions for cardiovascular disease self-management: a systematic review. Eur J Prev Cardiol 2015;23:801-17.

51. Surka S, Edirippulige S, Steyn $\mathrm{K}$, et al. Evaluating the use of mobile phone technology to enhance cardiovascular disease screening

by community health workers. Int J Med Inform 2014;83:648-54.

52. Chan CV, Kaufman DR. Mobile phones as mediators of health behavior change in cardiovascular disease in developing countries. Stud Health Technol Inform 2009;143:453-8.

53. Digital Trends. The number of smartphone users in the world is expected to reach a giant 6.1 billion by 2020. http://www. digitaltrends.com/mobile/ smartphone-users-number-6-1-billion-by-2020/. 2016.

54. Cooney MT, Dudina A, D'Agostino R, et al. Cardiovascular risk-estimation systems in primary prevention: do they differ? Do they make a difference? Can we see the future? Circulation 2010;122:300-10.

55. Feigin VL, Krishnamurthi R, Bhattacharjee R, et al. New strategy to reduce the global burden of stroke. Stroke 2015:46:1740-7.

56. Mancia G, Fagard R, Narkiewicz K, et al. 2013 ESH/ESC guidelines for the management of arterial hypertension: the Task Force for the management of arterial hypertension of the European Society of Hypertension (ESH) and of the European Society of Cardiology (ESC). J Hypertens 2013;31:1281-357.

57. Gluckman TJ, Kovacs RJ, Stone NJ, et al. The ASCVD risk estimator app: from concept to the current state. J Am Coll Cardiol 2016;67:350-2.

58. Riddell T, Wells S, Jackson R, et al. Performance of Framingham cardiovascular risk scores by ethnic groups in New Zealand: PREDICT CVD-10. N Z Med J 2010;123:50-61.

59. Hill S, Spink J, Cadilhac D, et al. Absolute risk representation in cardiovascular disease prevention: comprehension and preferences of health care consumers and general practitioners involved in a focus group study. BMC Public Health 2010;10:108.

60. Fagerlin A, Zikmund-Fisher BJ, Ubel PA. Helping patients decide: ten steps to better risk communication. J Natl Cancer Inst 2011:103:1436-43.

61. African Health Observatory World Health Organization [Internet]. (cited 10 March 2015). https://www.aho.afro.who.int/en/blog/2015/03/ 10/mobile-health-transforming-face-health-service-delivery-africanregion

62. Licskai C, Sands TW, Ferrone M. Development and pilot testing of a mobile health solution for asthma self-management: asthma action plan smartphone application pilot study. Can Respir $J$ 2013;20:301-6.

63. Ly KH, Carlbring P, Andersson G. Behavioral activation-based guided self-help treatment administered through a smartphone application: study protocol for a randomized controlled trial. Trials 2012;13:62.

64. Jenkins C, Burkett N-S, Ovbiagele B, et al. Stroke patients and their attitudes toward mHealth monitoring to support blood pressure control and medication adherence. mHealth 2016;2:24.

65. Feigin VL, Norrving B. A new paradigm for primary prevention strategy in people with elevated risk of stroke. Int J Stroke 2014;9:624-6.

66. Norrving B, Davis SM, Feigin VL, et al. Stroke prevention worldwide-what could make it work. Neuroepidemiology 2015;45:215-20.

67. Parmar P, Krishnamurthi R, Ikram MA, et al. The Stroke Riskometer ${ }^{\mathrm{TM}}$ app: validation of a data collection tool and stroke risk predictor. Int J Stroke 2015;10:231-44.

68. Morgan J. The power of the App: can mobile-technology save lives? Lancet Neurol 2015;15:668.

69. Doctors Choose the Best Health Apps of 2014. HealthTap. http:// www.healthtap.com/top_health_apps_2014

70. Ordúñez $P$, Tajer $\mathrm{C}$. Disseminating cardiovascular disease risk assessment with a PAHO mobile app: a public eHealth intervention. Rev Panam Salud Publica 2015;38:82-5. 
71. Kulshreshtha A, Vaccarino V, Judd SE, et al. Life's simple 7 and risk of incident stroke: the reasons for geographic and racial differences in stroke study. Stroke 2013;44:1909-14.

72. Cardiovascular disease prevention and control. Translating evidence into practice. Geneva: World Health Organization, 2005.

73. Neil HAW, Perera R, Armitage JM, et al. Estimated 10-year cardiovascular risk in a British population: results of a national screening project. Int J Clin Pract 2008;62:1322-31.

74. Blomstedt $\mathrm{Y}$, Norberg $\mathrm{M}$, Stenlund $\mathrm{H}$, et al. Impact of a combined community and primary care prevention strategy on all-cause and cardiovascular mortality: a cohort analysis based on 1 million person-years of follow-up in Västerbotten County, Sweden, during 1990-2006. BMJ Open 2015;5:e009651.

75. Ogunmoroti O, Allen NB, Cushman M, et al. Association between life's simple 7 and noncardiovascular disease: the multi-ethnic study of atherosclerosis. J Am Heart Assoc 2016;5:e003954.

76. World Health Organization. mHealth: new horizons for health through mobile technologies. Global observatory for eHealth series. Vol. 3. Geneva: WHO, 2011:1-99.

77. Turakhia MP, Desai SA, Harrington RA. The outlook of digital health for cardiovascular medicine: challenges but also extraordinary opportunities. JAMA Cardiol 2016;1:743-4. 